\title{
Enhancement of mechanochemical self-blocking and self-healing of early minor damages in polymers through hyperbranched architecture
}

\author{
M. X. Li, M. Z. Rong, M. Q. Zhang* \\ Key Laboratory for Polymeric Composite and Functional Materials of Ministry of Education, GD HPPC Lab, School of \\ Chemistry, Sun Yat-sen University, 510275 Guangzhou, P. R. China
}

Received 2 January 2021; accepted in revised form 22 February 2021

\begin{abstract}
For more effective removal of the hidden troubles from early minor damages before their spreading out, hyperbranched polyurethane crosslinked by dioxyphenylalanine- $\mathrm{Fe}^{3+}\left(\mathrm{DOPA}-\mathrm{Fe}^{3+}\right)$ and histidine- $\mathrm{Zn}^{2+}\left(\mathrm{His}^{3} \mathrm{Zn}^{2+}\right)$ coordination bonds is synthesized. By taking advantage of the cascading variation of the two types of metal-ligand complexations under the applied force, the growth of minor damages is firstly blocked, and then rehabilitation of the blocked damages takes place without manual intervention. Moreover, the experimental results indicate that the specific structure of hyperbranched macromolecules, which possess plenty of functional groups and great mobility, benefits to construct a stronger network with rapid response than that derived from the linear macromolecules. As a result, the stress-induced micro-voids in the crosslinked hyperbranched polyurethane are much smaller, and its robustness is allowed to be maintained to a higher extent, which is consistent with the concept of timely repairing upon destruction.
\end{abstract}

Keywords: smart polymers, metal-ligand complexation, hyperbranched polyurethane, mechanical properties, self-healing

\section{Introduction}

Self-healing represents a smart solution for the elimination of microcracks in polymers generated during manufacturing and/or service, which greatly enhances the durability and stability of the relevant products [1-4]. So far, however, the available self-healing strategies only prove to be applicable for the rehabilitation of macroscopic fractures when the external force exceeds the load-carrying limits of the materials [5-11]. Recovery of early minor damages that appear at low stress levels has not yet been considered. Evidently, it is rather meaningful in case the local stress concentration initiated damage precursors can be healed in time before their coalescence and growth. Early intervention is better than cure, after all.

For this purpose, our group recently proposed a novel approach under the inspiration of mussel byssus structure and $\mathrm{pH}$ dependence of metal-ligand coordination interactions [12]. Polyurethane served as the proof-of-concept polymer, whose soft and hard segments were crosslinked by the coordination bonds of dioxyphenylalanine- $\mathrm{Fe}^{3+}\left(\mathrm{DOPA}-\mathrm{Fe}^{3+}\right)$ and histidine- $\mathrm{Zn}^{2+}\left(\right.$ His- $\left.\mathrm{Zn}^{2+}\right)$, respectively. By controlling the synthesis conditions, both the two metal-ligand crosslinkages were adjusted to be bis-complexations in advance [13-15]. Upon loading, the weaker His$\mathrm{Zn}^{2+}$ bonds $[16,17]$ in the crosslinked polyurethane had to be preferentially dissociated, and the imidazole rings of the unbound histidine ligands raised the microenvironmental $\mathrm{pH}$ [12]. Accordingly, the adjacent bis-DOPA- $\mathrm{Fe}^{3+}$ bonds changed to tris-coordination as driven by the alkalinity, which factually increased the amount of the chains to be connected to the DOPA- $\mathrm{Fe}^{3+}$ cross-linkages, i.e. crosslink density [18].

$\overline{{ }^{*} \text { Corresponding author, e-mail: ceszmq@mail.sysu.edu.cn }}$ (C) BME-PT 
Owing to the temporarily increased crosslinking density, the polyurethane is strengthened so that the micro-voids were blocked instead of development. When the applied force was removed, the minor damages were closed along with the contraction of the deformed polyurethane network. In the meantime, the imidazole rings of the unbound histidine ligands attached to the soft segments easily re-associated with the neighboring free $\mathrm{Zn}^{2+}[19]$. As a result, the minor damages originating from broken His- $\mathrm{Zn}^{2+}$ bonds were restored, and the microenvironmental $\mathrm{pH}$ was recovered by the reduced amount of the free imidazole rings. Eventually, the trisDOPA- $\mathrm{Fe}^{3+}$ bonds transformed from bis-DOPA- $-\mathrm{Fe}^{3+}$ bonds also returned to the original status. Such mechanochemically initiated cascading variation of metal-ligand coordination bonds proved to proceed repeatedly without manual intervention.

It is worth noting that our preliminary experiments were conducted using linear polyurethane as the starting material. Since hyperbranched polymer has less entanglement than linear ones and facilitates slippage among the chain segments, which would offer higher mobility to the networked structure and match the requirement for the cascading reactions of the dynamic coordination bonds [20], we plan to examine the performance of hyperbranched polyurethane crosslinked by DOPA-Fe ${ }^{3+}$ and His- $\mathrm{Zn}^{2+}$ bonds following the same way like the linear version, in hopes of verifying and improving the capability of autonomous sustaining of robustness. This is the objective of the present work.

\section{Experimental}

\subsection{Materials and Instrumentation}

Analytical grade polytetrahydrofuran (PTMEG, $M_{\mathrm{n}}=$ 2000), isophorone diisocyanate (IPDI), dimethylformamide (DMF), dibutyltin dilaurate (DBTDL), hydroxyl-terminated hyperbranched polyester $\left(n_{(-\mathrm{OH})}=\right.$ $12, M_{\mathrm{n}} \approx 1250$ ), $n$-(tert-butoxycarbonyl)-L-Histidine (Boc-L-Histidine), dicyclohexylcarbodiimide (DCC), 1-hydroxybenzotriazole (Hobt), 2-amino-1,3-propanediol (SERINOL), dopamine hydrochloride, homocysteine thiolactone hydrochloride, sodium bicarbonate, tetrahydrofuran (THF), ferric chloride, zinc chloride and triethylamine (TEA) were purchased from Sigma-Aldrich and used as received without further purification. Hydroxyl-terminated hyperbranched polyester $\left(n_{(-\mathrm{OH})}=12, M_{\mathrm{n}} \approx 1250\right)$ was purchased from Wuhan Hyperbranched Polymer Science \& Technology Co., Ltd, China.

Fourier transform infrared (FTIR) spectra were recorded using a Bruker EQUINOX55 (Bruker, Germany) spectrophotometer between $400-4000 \mathrm{~cm}^{-1}$ with a resolution of $4 \mathrm{~cm}^{-1}$ by the $\mathrm{KBr}$ sample holder method.

Proton nuclear magnetic resonance ( ${ }^{1} \mathrm{H}$ NMR) spectra were obtained by using DMSO- $d$ as the solvent on a Bruker AVANEC III (Bruker, Germany) spectrometer $(400 \mathrm{MHz})$.

Raman spectra were collected by a confocal Raman microscope (inVia, Reinshaw, UK) using an aircooled CCD behind a grating $\left(300 \mathrm{~g} \cdot \mathrm{mm}^{-1}\right)$ spectrograph with a spectral resolution of $4 \mathrm{~cm}^{-1}$. The diodepumped $785 \mathrm{~nm}$ near infrared laser excitation was employed in combination with a $20 \times$ microscope objective. To avoid burning by the laser beam, laser power of $10 \mathrm{~mW}$ and exposure time of $20 \mathrm{~s}$ were used for all the measurements.

Dynamic mechanical analysis (DMA) of dumbbellshaped specimens $\left(2 \times 3 \times 10 \mathrm{~mm}^{3}\right)$ was performed by a Mettler Toledo Instrument DMA SDTA861 (Mettler Toledo, USA) with tensile mode under $0.5 \mathrm{~Hz}$ with a heating rate of $5{ }^{\circ} \mathrm{C} / \mathrm{min}$ in nitrogen. The molecular weight between crosslinks, $M_{\mathrm{c}}$, was estimated from the Equation (1):

$G^{\prime}=\frac{\rho}{M_{\mathrm{c}}} R T$

where $G^{\prime}$ is the storage modulus at room temperature, $\rho$ density, $R$ gas constant, and $T$ absolute temperature. Stress relaxation tests were carried out at room temperature on the same type of specimens using the same DMA instrument with a tensile mode at a strain of $50 \%$.

Tensile tests were conducted on dumbbell-shaped specimens $\left(2 \times 3 \times 10 \mathrm{~mm}^{3}\right)$ with a SANS CMT6103 (SANS, China) universal tester at a crosshead speed of $50 \mathrm{~mm} / \mathrm{min}$ under room temperature. Repeated loading/unloading tensile tests were conducted with the same tester at room temperature. The crosshead speed for the loading test was $50 \mathrm{~mm} / \mathrm{min}$, and that for unloading was $5 \mathrm{~mm} / \mathrm{min}$.

Fatigue tests of the specimen $\left(50 \times 10 \times 1 \mathrm{~mm}^{3}\right)$ with a pre-crack of $2 \mathrm{~mm}$ [21] were carried out by means of an ADT-AV02 fatigue testing machine (Shimadzu, Japan). The crack development was recorded by 

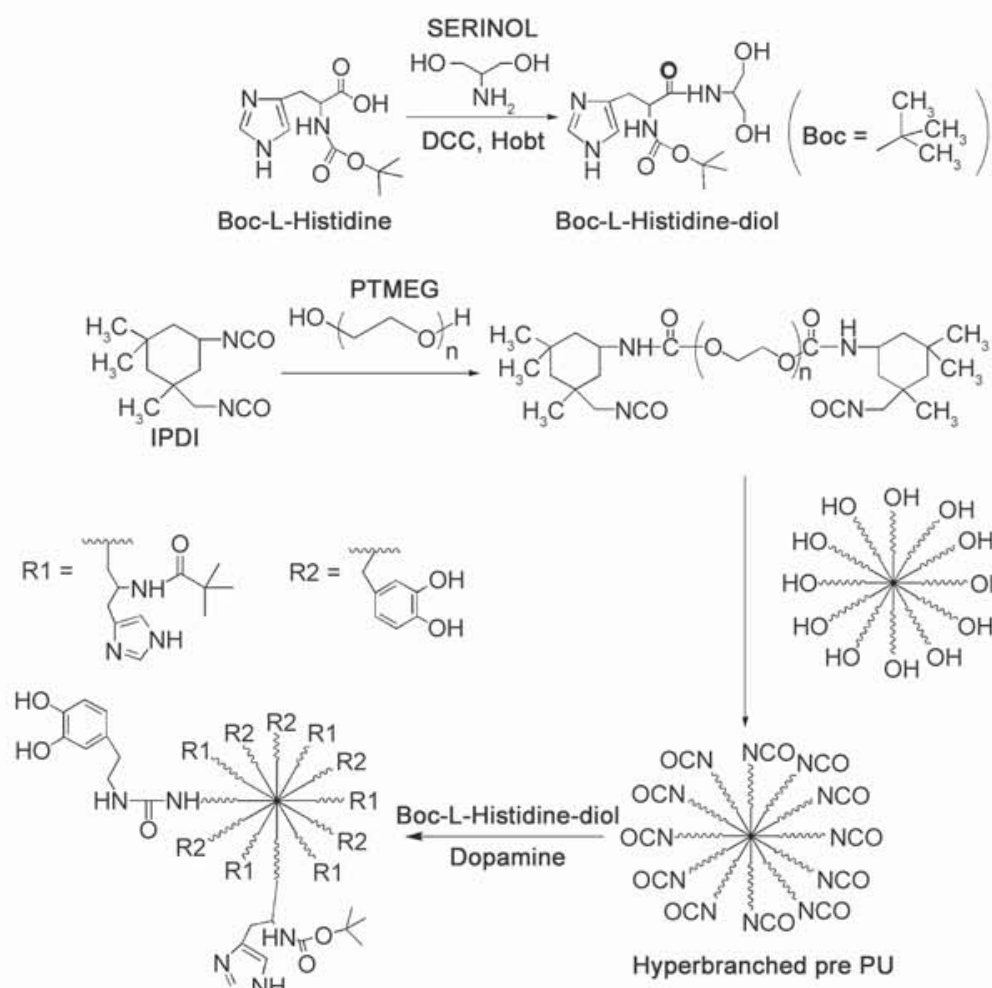

a)

Hyperbranched pre PU

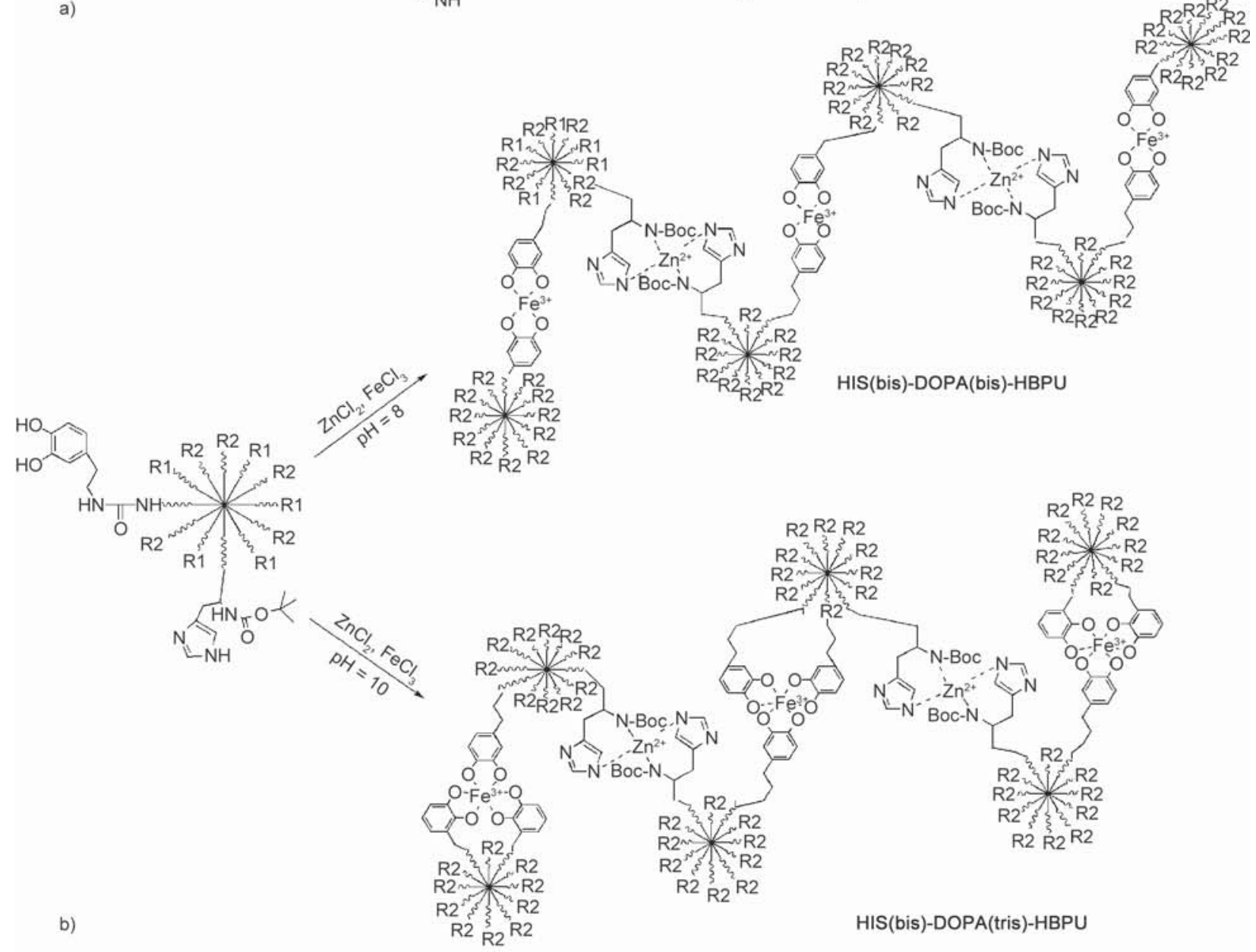

Figure 1. Synthesis of (a) hyperbranched polyurethane prepolymer and (b) its crosslinked versions. 
photographs, and then the crack length was measured by post-processing of the pictures.

Porosity analysis was performed by an ASAP2010 Micrometrics apparatus (Micrometrics, USA) using nitrogen as the adsorbate.

\subsection{Synthesis}

Figure 1 shows the synthesis of the target polymer, crosslinked hyperbranched polyurethane. The key component, Boc-L-Histidine-diol (Figure 1a), was prepared as described elsewhere [12].

Firstly, the hyperbranched polyurethane prepolymer was obtained as follows. PTMEG (10.0 g, $0.005 \mathrm{~mol})$ was dissolved in DMF, and then IPDI $(2.22 \mathrm{~g}$, $0.01 \mathrm{~mol}$ ) that had been dissolved in DMF in advance was added dropwise under nitrogen protection with mechanical stirring. Then, two drops of DBTDL were added as the catalyst, and the prepolymerization was carried out at $60^{\circ} \mathrm{C}$ for $5 \mathrm{~h}$. Afterward, the DMF solution of hyperbranched polyester $(0.520 \mathrm{~g}$, $\left.4.02 \cdot 10^{-4} \mathrm{~mol}\right)$ was incorporated into the system at $40^{\circ} \mathrm{C}$. When the reaction lasted $3 \mathrm{~h}$, Boc-L-Histidinediol $(0.82 \mathrm{~g}, 0.0025 \mathrm{~mol})$ was added, and the reaction was conducted for an additional $3 \mathrm{~h}$. Eventually, the mixture was cooled down to $30^{\circ} \mathrm{C}$, and dopamine hydrochloride $(0.47 \mathrm{~g}, 0.0025 \mathrm{~mol})$ was added, which was followed by incorporating drops of triethylamine to neutralize the hydrochloric acid. Then, the mixture was allowed to react for $3 \mathrm{~h}$ under stirring.

Secondly, $\mathrm{FeCl}_{3}$ and $\mathrm{ZnCl}_{2}$ were chosen as the ligands to coordinate with DOPA and HIS groups, respectively (Figure 1b) $[14,16]$. Since DOPA is capable of forming complex with divalent and trivalent metal ions and His groups can only chelate divalent metal ions [16], $\mathrm{FeCl}_{3}$ (0.203 g, $\left.0.00125 \mathrm{~mol}\right)$ was added to the above polyurethane prepolymer solution at an $\mathrm{Fe}^{3+} / \mathrm{DOPA}$ molar ratio of 1:2 [14], to avoid the DOPA groups from being affected by $\mathrm{ZnCl}_{2}$. After 30 min under stirring, $\mathrm{ZnCl}_{2}(0.168 \mathrm{~g}$, $0.00125 \mathrm{~mol}$ ) was added, and TEA was used to adjust the $\mathrm{pH}$ of the system to be 8 . Finally, the solvent was partially removed, and the remaining fluid was poured into a square mold. The ultimate crosslinked hyperbranched polyurethane film with bis-coordinated HIS- $\mathrm{Zn}^{2+}$ and DOPA-Fe ${ }^{3+}$ (code name: HIS (bis)-DOPA(bis)-HBPU) was yielded after vaporing the residual solvent in a drying oven. Besides, the crosslinked hyperbranched polyurethane with biscoordinated HIS- $\mathrm{Zn}^{2+}$ and tris-coordinated DOPA$\mathrm{Fe}^{3+}$ (code name: HIS(bis)-DOPA(tris)-HBPU) was prepared via the same procedures except that the system $\mathrm{pH}$ was tuned to be 10 and fewer $\mathrm{FeCl}_{3}(0.135 \mathrm{~g}$, $\left.8.32 \cdot 10^{-4} \mathrm{~mol}\right)$ was incorporated to ensure $\mathrm{Fe}^{3+} /$ DOPA molar ratio of 1:3.

\section{Results and discussion}

The chemical structure of the polyurethane prepolymer is verified by FTIR (Figure 2a) and ${ }^{1} \mathrm{H}$ NMR (Figure 2b) spectra, respectively. The strong absorbances at 1540 and $1735 \mathrm{~cm}^{-1}$ on the FTIR spectra represent typical $-\mathrm{NH}-$ and $\mathrm{C}=\mathrm{O}$ groups of polyurethane. Besides, the assignments of the ${ }^{1} \mathrm{H}$ NMR signals are given below: 7.55-7.69 ppm $(\mathrm{d}$, $2 \mathrm{H},-\mathrm{CH}=$ of imidazole ring), $6.82-6.95 \mathrm{ppm}(\mathrm{d}, 3 \mathrm{H}$, $\mathrm{CH}=\mathrm{CH}$ of catechol $), 4.05$ and $4.5\left(\mathrm{~d},{ }^{1} \mathrm{H},-\mathrm{NH}-\right.$ resulting from the reaction between - $\mathrm{NCO}$ groups and reactive hydrogen), 3.32 and $3.61\left(\mathrm{~d}, 4 \mathrm{H},-\mathrm{CH}_{2}-\mathrm{CH}_{2}-\right.$ of all the reagent), $1.35-1.48\left(\mathrm{~d}, 6 \mathrm{H},-\mathrm{CH}_{3}\right.$ of IPDI and histidine). The results demonstrate that the histidine and dopamine groups have been included in the polymer chains as expected.

The successfully formation of His- $\mathrm{Zn}^{2+}$ and DOPA$\mathrm{Fe}^{3+}$ coordination bonds is verified by the Raman spectrum (Figure 2c), as the peaks at the Raman shifts of around 660 and $1580 \mathrm{~cm}^{-1}$ are assigned to DOPA$\mathrm{Fe}^{3+}$ and His- $\mathrm{Zn}^{2+}$ coordination, respectively $[17,22]$. To understand the fundamental structural details of the resultant crosslinked hyperbranched polyurethane, its dynamic mechanical properties are measured (Figure 3 ). It is seen that only a single $T_{\mathrm{g}}$ peak resulting from the soft segments appears at $-50^{\circ} \mathrm{C}$, meaning that microphase separation in conventional polyurethane does not exist. The situation is similar to the linear polyurethane crosslinked by the same DOPA-Fe ${ }^{3+}$ and HIS- $\mathrm{Zn}^{2+}$ bonds (HIS(bis)-DOPA (bis)-PU, $T_{\mathrm{g}}=-53^{\circ} \mathrm{C}$ ) [12]. Besides, the molecular weight between crosslinks, $M_{\mathrm{c}}$, of HIS(bis)-DOPA (bis)-HBPU is $3.1 \cdot 10^{3} \mathrm{~g} / \mathrm{mol}$, which is lower than that of HIS(bis)-DOPA(bis)-PU $\left(M_{\mathrm{c}}=4.5 \cdot 10^{3} \mathrm{~g} / \mathrm{mol}\right)$. The difference may originate from the fact that the hyperbranched polyurethane prepolymer contains more functional groups than the linear version since both of the crosslinked ones possess almost the same mass fraction of the coordination bonds. As a result of the higher crosslinking density, HIS(bis)-DOPA (bis)-HBPU exhibits obviously higher tensile strength than HIS(bis)-DOPA(bis)-PU (Figure 4). On the other hand, the elongation at break of the former is also higher than that of the latter. The reduced entanglement ability of the hyperbranched macromolecules, 


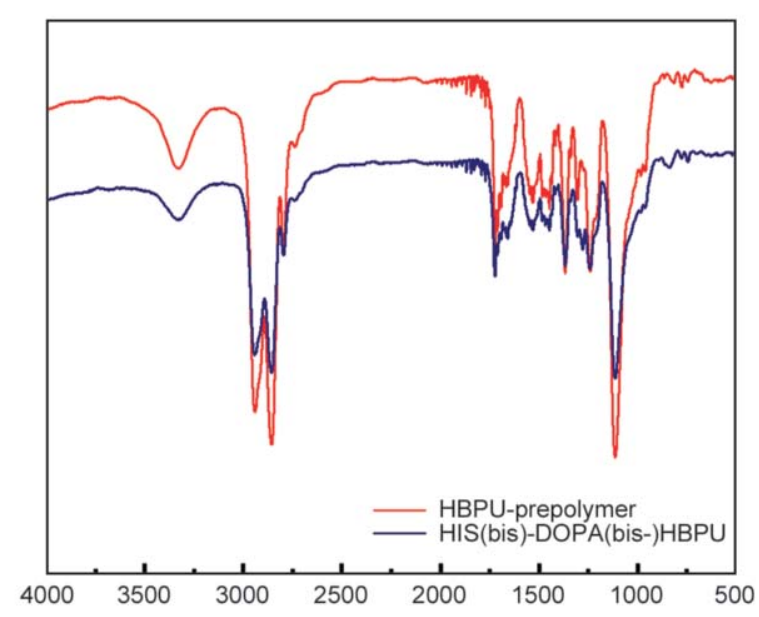

a)

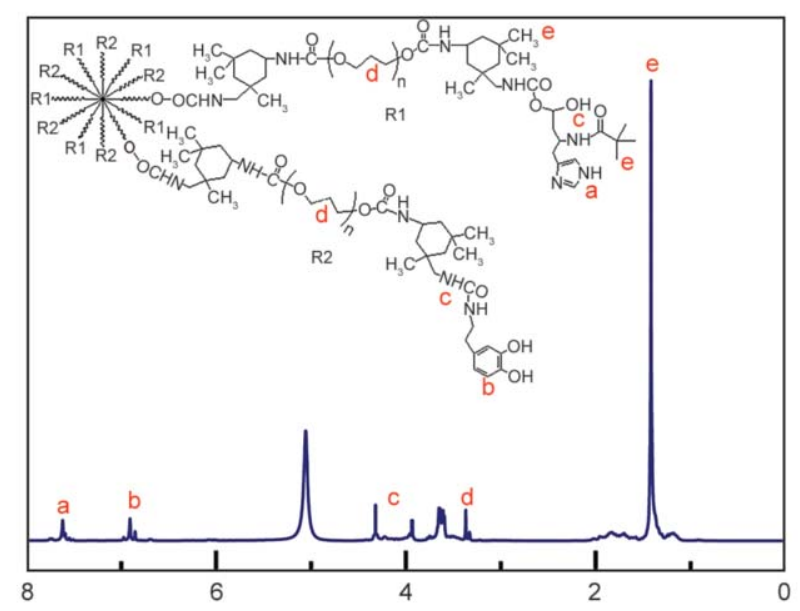

b)

Chemical shift [ppm]

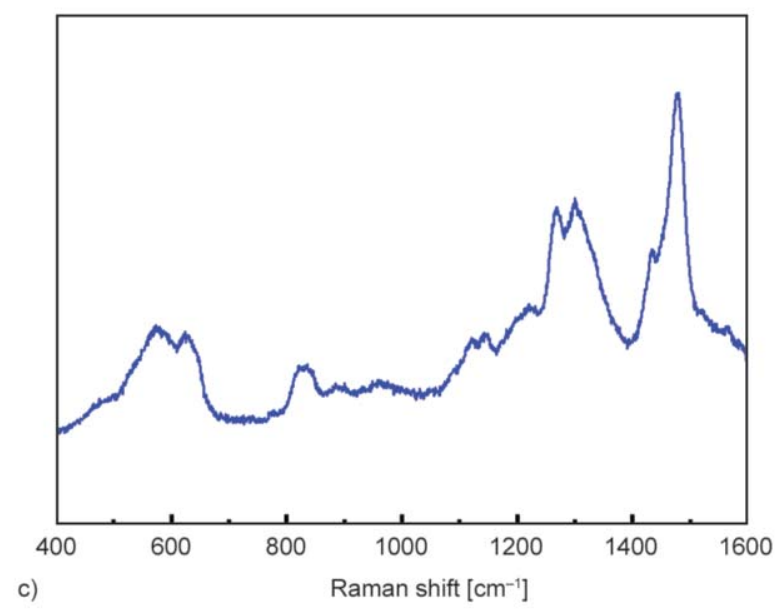

Figure 2. Characterization of the chemical structures of $(a, b)$ the hyperbranched polyurethane prepolymer and (c) its crosslinked version HIS(bis)-DOPA(bis)-HBPU. (a) FTIR spectra; (b) ${ }^{1} \mathrm{H}$ NMR spectrum; (c) Raman spectrum.

which favors relative movement among the polyurethane chains, must take responsibility.

Our previous study indicated that the dynamic reversibility of DOPA-Fe ${ }^{3+}$ complexation could be

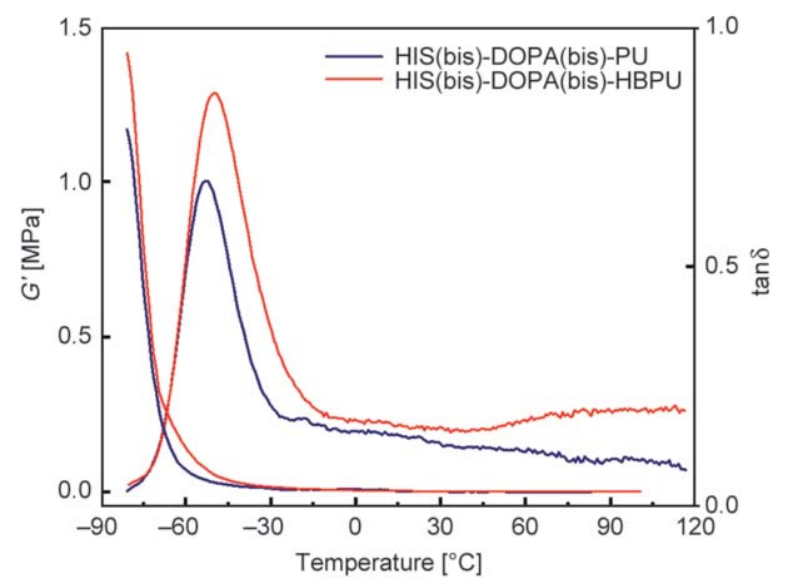

Figure 3. Temperature dependences of storage modulus, $G^{\prime}$, and loss factor, $\tan \delta$, of HIS(bis)-DOPA(bis)-PU and HIS(bis)-DOPA(bis)-HBPU (rate of heating: $3{ }^{\circ} \mathrm{C} / \mathrm{min}$; frequency: $1 \mathrm{~Hz}$ ). triggered by water [20], and the mechanochemical cascading variation of metal-ligand coordination bonds are allowed to take place in hydrated HIS(bis)-DOPA(bis)-PU [12]. According to these

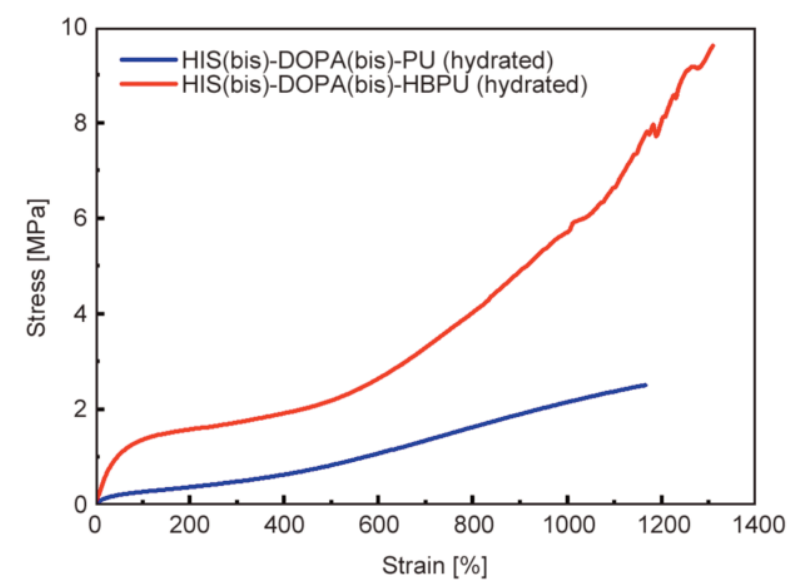

Figure 4 Typical tensile stress-strain curves of HIS(bis)DOPA(bis)-PU and HIS(bis)-DOPA(bis)-HBPU. 
findings, the present HIS(bis)-DOPA(bis)-HBPU is also immersed in water till saturation for the subsequent experiments. The stress relaxation tests demonstrate that the unusual stress intensification appears for both hydrated HIS(bis)-DOPA(bis)-PU and HIS(bis)-DOPA (bis)-HBPU (Figure 5a). Clearly, the coordinatively unsaturated bis-DOPA- $\mathrm{Fe}^{3+}$ bonds are able to be transformed into tris-coordination under the catalysis of the alkalinity offered by the free imidazole rings of unbound histidine ligands from the preferentially cleft weaker His- $\mathrm{Zn}^{2+}$ bonds upon tension. With increasing time, more and more bis-DOPA- $\mathrm{Fe}^{3+}$ bonds in the crosslinked polymers turn to be tris-DOPA- $\mathrm{Fe}^{3+}$ bonds, and the crosslinking density keeps raising. Stress intensification [2325], rather than stress relaxation, is thus observed in the latter stage of the test. Interestingly, the rising slope of hydrated HIS (bis)-DOPA(bis)-HBPU is higher than HIS(bis)-DOPA(bis)-PU, owing to the quick responsivity of the hyperbranched molecules. The repeated loading/ unloading tensile tests of the materials (Figure $5 \mathrm{~b}$ ) reflect the feature of hydrated HIS(bis)-DOPA(bis)-HBPU from another angle. Except for the first hysteresis loop caused by permanent plastic deformation, the rest hysteresis loops almost overlap each other, showing that the rearrangement of the networks is able to take place to accommodate the applied force. More importantly, the residual strains after unloading of hydrated HIS(bis)DOPA(bis)-HBPU are smaller than those of hydrated HIS(bis)-DOPA(bis)-PU. It means that the damages created in the course of stretching can be more effectively repaired by the former.

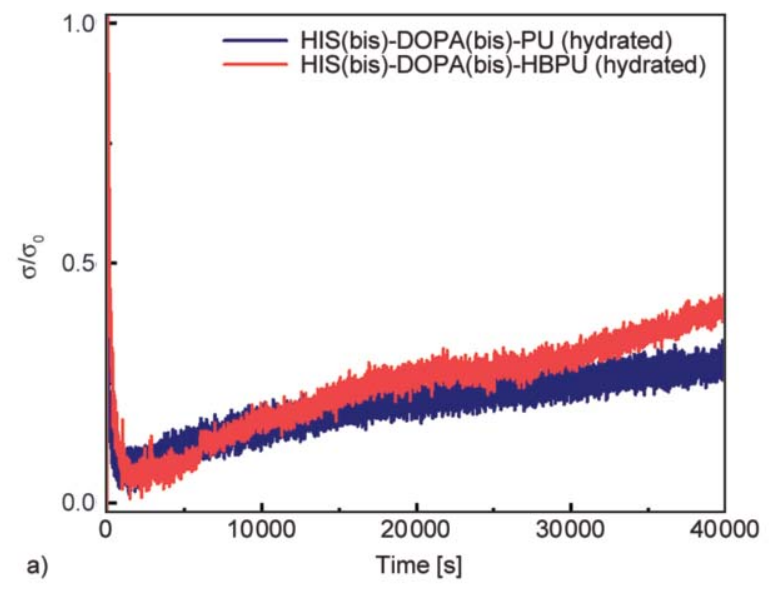

The above experiments imply that the mechanochemistry-enabled structural safety protection mechanisms can take effect as expected.

In this context, we start to evaluate the capability of autonomous sustaining robustness of the materials. Here the robustness is quantified by the ratio between the tensile strength of the specimen that has been subjected to repeated pre-stretching and that of the virgin specimen. Since the damage precursors derived from broken molecular chains would grow up during the repeated stretching, the mechanical strength of the material has to gradually decrease unless the development of the small damages can be stopped and healed. Therefore, one hundred percent robustness represents that the tiny wounds are completely blocked and recovered.

Table 1 lists the robustness, $R_{\mathrm{n}}$, of different materials calculated according to the above definition. The hydrated HIS(bis)-DOPA(tris)-PU and HIS(bis)-DOPA (tris)-HBPU exhibited rather low robustness because their reversible DOPA- $\mathrm{Fe}^{3+}$ bonds have reached the highest degree of coordination. Although the mechanically active His- $\mathrm{Zn}^{2+}$ bonds can still be dissociated under tension, releasing free imidazole rings, there are no bis-DOPA- $\mathrm{Fe}^{3+}$ coordination bonds in the polymers. Since the crosslink density of the polymer networks, i.e., their strength, remains unchanged, the growth of damages derived from dissociated His$\mathrm{Zn}^{2+}$ bonds has to be promoted instead of being timely hindered. The restoration of His- $\mathrm{Zn}^{2+}$ bonds accompanying the subsequent unloading may heal a few small cracks, but the larger cracks (e.g., $\sim 300 \mathrm{~nm}$, refer to Table 2) are hard to be recovered as the

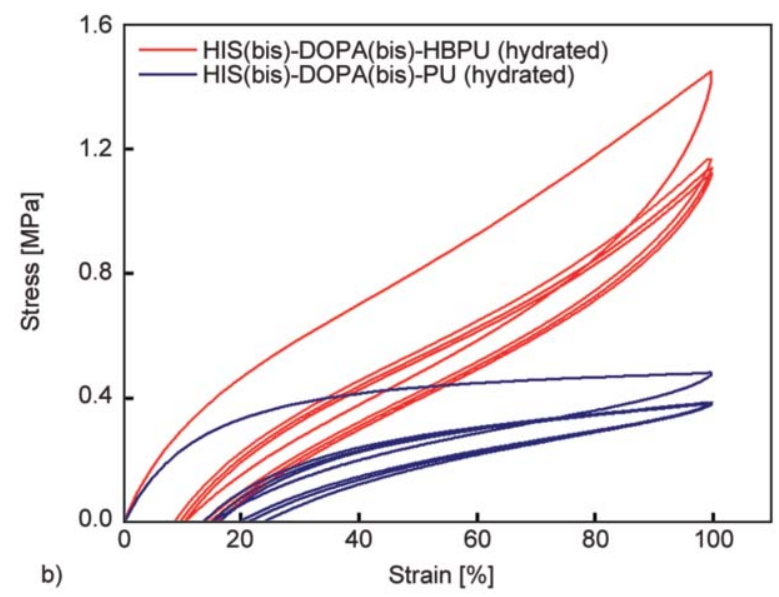

Figure 5. (a) Stress relaxation behaviors and (b) tensile stress-strain curves recorded during cyclic loading and unloading tests of hydrated HIS(bis)-DOPA(bis)-PU and HIS(bis)-DOPA(bis)-HBPU. After each loading/unloading cycle, the specimen is allowed to take a 12 hour break. 
Table 1. Robustness of the crosslinked polyurethanes (unit: \%).

\begin{tabular}{|c|c|c|c|c|c|c|c|c|c|}
\hline \multirow{2}{*}{$\begin{array}{l}\text { Pre-stretching } \\
\text { time }\end{array}$} & \multirow[t]{2}{*}{ Material } & \multicolumn{3}{|c|}{$\begin{array}{c}\text { Strain of pre-stretching } \\
{[\%]}\end{array}$} & \multirow{2}{*}{$\begin{array}{l}\text { Pre-stretching } \\
\text { time }\end{array}$} & \multirow[t]{2}{*}{ Material } & \multicolumn{3}{|c|}{$\begin{array}{c}\text { Strain of pre-stretching } \\
{[\%]}\end{array}$} \\
\hline & & 150 & 180 & 250 & & & 150 & 180 & 250 \\
\hline 1 & \multirow{5}{*}{ 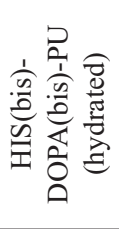 } & 87 & 85 & 80 & 1 & \multirow{5}{*}{ 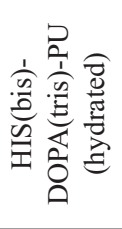 } & 41 & 35 & 21 \\
\hline 2 & & 87 & 85 & 78 & 2 & & 35 & 29 & 15 \\
\hline 3 & & 87 & 85 & 77 & 3 & & 21 & 20 & 11 \\
\hline 4 & & 87 & 85 & 75 & 4 & & 14 & 13 & 10 \\
\hline 5 & & 87 & 83 & 74 & 5 & & 11 & 10 & 10 \\
\hline 1 & \multirow{5}{*}{ 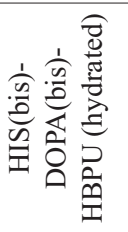 } & 92 & 90 & 87 & 1 & \multirow{5}{*}{ 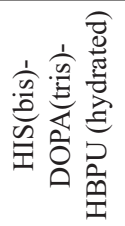 } & 47 & 45 & 39 \\
\hline 2 & & 92 & 90 & 86 & 2 & & 38 & 33 & 25 \\
\hline 3 & & 91 & 90 & 86 & 3 & & 25 & 22 & 29 \\
\hline 4 & & 91 & 90 & 86 & 4 & & 21 & 17 & 17 \\
\hline 5 & & 91 & 90 & 86 & 5 & & 19 & 15 & 17 \\
\hline
\end{tabular}

The robustness, $R_{\mathrm{n}}$, was determined following the procedures described elsewhere [12]. $R_{\mathrm{n}}=\sigma_{\mathrm{n}} / \sigma_{0}$, where $\sigma_{0}$ is the tensile strength of the original specimen, and $\sigma_{\mathrm{n}}$ is the tensile strength of the specimen pre-stretched to certain strain for $n$ times. After each pre-stretching, the specimen takes a rest of $12 \mathrm{~h}$.

interstitial gaps are too wide to enable solid-phase reaction across the interface [26]. Consequently, the robustness values greatly decrease with increasing the pre-stretching times and strain.

In contrast, both hydrated HIS(bis)-DOPA(bis)-PU and HIS(bis)-DOPA(bis)-HBPU possess rather high robustness, despite that the robustness values also decrease with a rise in the pre-stretching strain. In comparison with the specimens containing trisDOPA- $\mathrm{Fe}^{3+}$ bonds, it is evident that the mechanochemically induced cascading variation of the metalligand coordination bonds must have taken place in the ones having bis-DOPA- $\mathrm{Fe}^{3+}$ bonds. The transformation of bis-DOPA- $\mathrm{Fe}^{3+}$ coordination bonds into tris-versions successfully suppresses the microcrack growth. The self-blocking effect cooperates with the self-healing effect based on reformation of His- $\mathrm{Zn}^{2+}$ complexation, which prevents the materials from remarkable deterioration like the specimens whose crosslink density is fixed. Furthermore, a careful survey of Table 1 indicates that the hydrated HIS(bis)DOPA(bis)-HBPU has higher robustness than hydrated HIS(bis)-DOPA(bis)-PU. Again, the flexible hyperbranched structure of the former and the easily accessible coordination bonds around the hyperbranched macromolecular chains must benefit the mechanochemical processes. Because of it, the lowest robustness of hydrated HIS(bis)-DOPA(bis)HBPU in Table 1 is still as high as $86 \%$ at the prestretching strain of $250 \%$, which is $12 \%$ higher than that of hydrated HIS(bis)-DOPA(bis)-PU subjected to the same pre-stretching history.

It is worth noting that the current study is focused on the restoration of early minor damages, but these damages have not yet been characterized because they are too small to be detected. To tackle the challenge, we measure the micropores sizes of the polyurethanes by means of a porosimetry system that works on the basis of the gas sorption technique. As shown in Table 2, for the virgin hydrated HIS(bis)DOPA(bis)-PU, whose average pore size is $\sim 2.4 \mathrm{~nm}$. When the specimen is pre-stretched, the micropores turn to be $\sim 28.6 \mathrm{~nm}$ as a result of stress-induced micro-void growth. Thanks to its self-healing capability, the pore size becomes $10.2 \mathrm{~nm}$ after resting. Comparatively, the increase of pore size of the hydrated HIS(bis)-DOPA(tris)-PU from the original state to the pre-stretched state is much greater, because no

Table 2. Average pore sizes of the hydrated crosslinked polyurethanes (unit: $\mathrm{nm}$ ).

\begin{tabular}{|l|c|c|c|c|}
\hline \multicolumn{1}{|c|}{ Specimen } & HIS(bis)-DOPA(bis)-PU & HIS(bis)-DOPA(tris)-PU & HIS(bis)-DOPA(bis)-HBPU & HIS(bis)-DOPA(tris)-HBPU \\
\hline Original & 2.39 & 1.91 & 3.67 & 1.91 \\
\hline Stretched & 28.62 & 317.19 & 35.03 & 306.58 \\
\hline $\begin{array}{l}\text { Rested after the } \\
\text { pre-stretching }\end{array}$ & 10.21 & 235.91 & 4.36 & 185.47 \\
\hline
\end{tabular}

Prior to the test, the virgin specimens are stretched to the strain of 500\% to breed the micro-voids, and then the stretched specimens are allowed to rest for $12 \mathrm{~h}$ for recovery. 

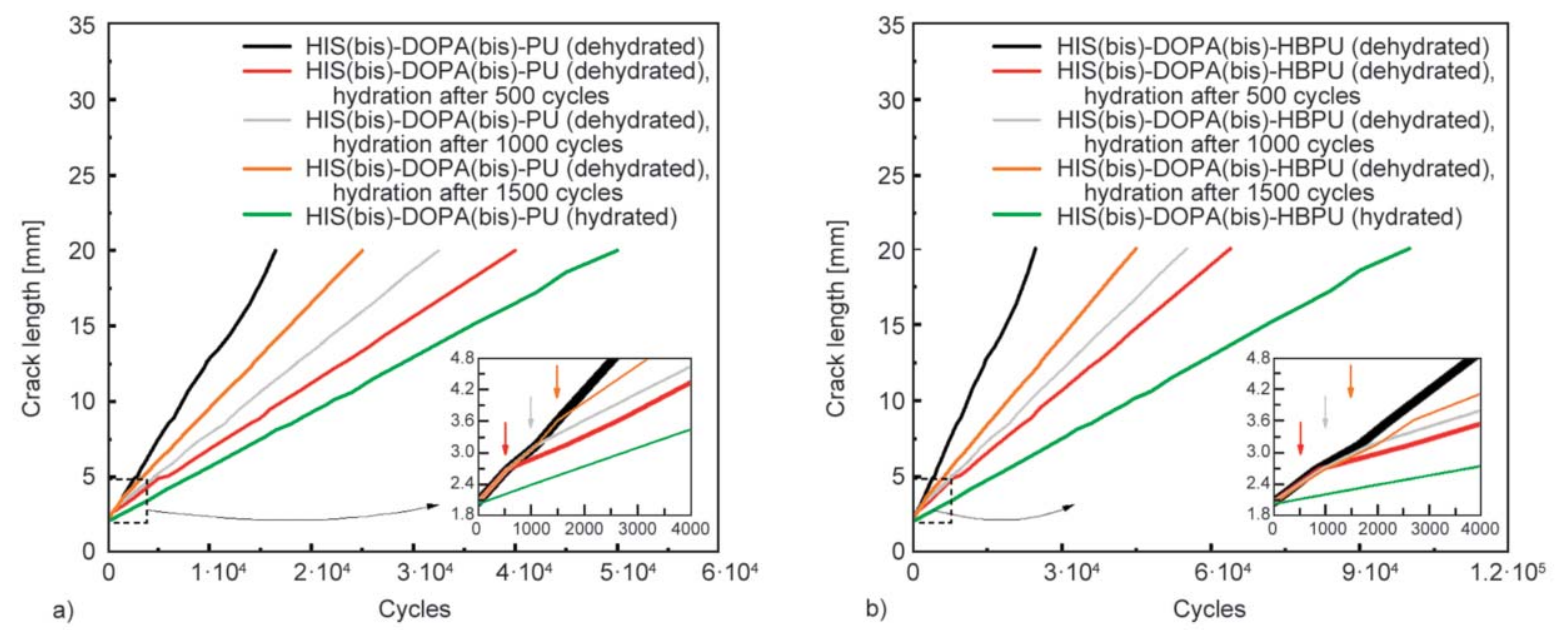

Figure 6. Crack length as a function of fatigue cycles of (a) HIS(bis)-DOPA(bis)-PU and (b) HIS(bis)-DOPA(bis)-HBPU. For the dehydrated specimens, the tests are paused after certain cycles, and the specimens are wrapped by the absorbent cotton saturated with water for $12 \mathrm{~h}$. Then, the tests restart.

more tris-DOPA-Fe ${ }^{3+}$ complexation can be formed in this case, and the crack blocking mechanism cannot take effect. Even a few damages can be restored during resting; the average pore size of the specimen is only marginally reduced to $235.9 \mathrm{~nm}$. With respect to the hyperbranched versions, the variation trends are the same as those made of linear polyurethane, but the pore sizes after resting are smaller under identical conditions. The results coincide with the robustness measurements. That is, the hyperbranched specimens have higher robustness than the counterparts based on linear polyurethane precursors, ascribing to the higher mobility and the synergistic effect of the nearby coordination bonds featured by hyperbranched polymers.

The positive contribution of the hyperbranched polymer is further revealed by the fatigue test. Figure 6 demonstrates that the in-situ hydration of the dehydrated specimens can significantly slow down the crack propagation and improve the fatigue life. This is because the DOPA- $\mathrm{Fe}^{3+}$ coordination bonds are activated by water, and the increased crosslinking density of the polymers resulting from the increased tris-DOPA- $\mathrm{Fe}^{3+}$ bonds obstructs the development of cracking due to the dissociation of His- $\mathrm{Zn}^{2+}$ bonds. Therefore, the later the specimens adsorb water, the more unrecoverable damages appear and the shorter fatigue life. Nevertheless, the hyperbranched specimens have a swifter response in comparison with the controls made from linear polyurethane. By taking the dehydrated specimens that adsorb water after 1500 cycles, for example, the rate of crack growth of the in-situ hydrated HIS(bis)-DOPA(bis)-HBPU is $\sim 61 \%$ of that of the dehydrated specimen, while the rate of crack growth of the in-situ hydrated HIS(bis)DOPA(bis)-PU is $\sim 66 \%$ of that of the dehydrated specimen. It means that the mechanochemistry aroused retardance of fatigue crack growth is more remarkable for the hyperbranched specimens. Consequently, their fatigue life becomes much longer.

\section{Conclusions}

The present work demonstrates that the concept of autonomous sustaining of the robustness of polymers based on reversible mechanochemistry can be implemented in hyperbranched polyurethane crosslinked by His- $\mathrm{Zn}^{2+}$ and DOPA-Fe ${ }^{3+}$ coordination bonds. The early minor damages in the polyurethane are successfully retarded and then restored by the molecular-level internal equilibrium protection mechanisms through cascading variation of the metal-ligand complexations. Accordingly, the adaptability and replicability of the strategy recently proposed by our group are evidenced. Taking advantage of high mobility and plenty adjacent functional groups, the hyperbranched architecture imparts higher mechanical properties, faster response speed, and greater ability to sustain robustness to the crosslinked polyurethane in comparison to the linear counterpart. In this context, the crosslinked hyperbranched polyurethane seems to be more feasible for future application.

\section{Acknowledgements}

This work was financially supported by the National Natural Science Foundation of China (Nos. 52033011, 51773229 and 51873235). 


\section{References}

[1] Bergman S. D., Wudl F.: Mendable polymers. Journal of Materials Chemistry, 18, 41-62 (2008).

https://doi.org/10.1039/B713953P

[2] Zhang Z. P., Rong M. Z., Zhang M. Q.: Polymer engineering based on reversible covalent chemistry: A promising innovative pathway towards new materials and new functionalities. Progress in Polymer Science, 80, 39-93 (2018).

https://doi.org/10.1016/j.progpolymsci.2018.03.002

[3] Pastine S. J., Okawa D., Zettl A., Fréchet J. M. J.: Chemicals on demand with phototriggerable microcapsules. Journal of the American Chemical Society, 131, 1358613587 (2009).

https://doi.org/10.1021/ja905378v

[4] Huynh T-P., Haick H.: Self-healing, fully functional, and multiparametric flexible sensing platform. Advanced Materials, 28, 138-143 (2016). https://doi.org/10.1002/adma.201504104

[5] White S. R., Sottos N. R., Geubelle P. H., Moore J. S., Kessler M. R., Sriram S. R., Brown E. N., Viswanathan S.: Autonomic healing of polymer composites. Nature, 409, 794-797 (2001). https://doi.org/10.1038/35057232

[6] Fakirov S.: Once more on the proper use of terms and definitions: This time about the term 'self-healing'. Express Polymer Letters, 15, 88 (2021). https://doi.org/10.3144/expresspolymlett.2021.9

[7] Zhao M., Tang Z., Zhang X., Li Z., Xiao H., Zhang M., Liu K., Ni Y., Huang L., Chen L., Wu H.: A self-healing, stretchable, and conductive poly $(N$-vinylpyrrolidone)/gallic acid composite hydrogel formed via hydrogen bonding for wearable electronic sensors. Composites Science and Technology, 198, 108294/1-108294/9 (2020).

https://doi.org/10.1016/j.compscitech.2020.108294

[8] Ouyang Z., Yu H-Y., Song M., Zhu J., Wang D.: Ultrasensitive and robust self-healing composite films with reinforcement of multi-branched cellulose nanocrystals. Composites Science and Technology, 198, 108300/1108300/8 (2020).

https://doi.org/10.1016/j.compscitech.2020.108300

[9] Amamoto Y., Kamada J., Otsuka H., Takahara A., Matyjaszewski K.: Repeatable photoinduced self-healing of covalently cross-linked polymers through reshuffling of trithiocarbonate units. Angewandte Chemie International Edition, 50, 1660-1663 (2011). https://doi.org/10.1002/anie.201003888

[10] Yoon J. A., Kamada J., Koynov K., Mohin J., Nicolay R., Zhang Y., Balazs A. C., Kowalewski T., Matyjaszewski K.: Self-healing polymer films based on thiol-disulfide exchange reactions and self-healing kinetics measured using atomic force microscopy. Macromolecules, 45, 142-149 (2012).

https://doi.org/10.1021/ma2015134
[11] Das M., Pal S., Naskar K.: Exploring various metal-ligand coordination bond formation in elastomers: Mechanical performance and self-healing behavior. Express Polymer Letters, 14, 860-880 (2020). https://doi.org/10.3144/expresspolymlett.2020.71

[12] Li M-X., Rong M-Z., Zhang M-Q.: Reversible mechanochemistry enabled autonomous sustaining of robustness of polymers - An example of next generation self-healing strategy. Chinese Journal of Polymer Science, 39, 545-553 (2021). https://doi.org/10.1007/s10118-021-2532-0

[13] Harrington M. J., Masic A., Holten-Andersen N., Waite J. H., Fratzl P.: Iron-clad fibers: A metal-based biological strategy for hard flexible coatings. Science, 328, 216-220 (2010). https://doi.org/10.1126/science.1181044

[14] Zeng H., Hwang D. S., Israelachvili J. N., Waite J. H.: Strong reversible $\mathrm{Fe}^{3+}$-mediated bridging between dopacontaining protein films in water. Proceeding of the National Academy of Sciences, 107, 12850-12853 (2010). https://doi.org/10.1073/pnas.1007416107

[15] Holten-Andersen N., Harrington M. J., Birkedal H., Lee B. P., Messersmith P. B., Lee K. Y. C., Waite J. H.: pHinduced metal-ligand cross-links inspired by mussel yield self-healing polymer networks with near-covalent elastic moduli. Proceeding of the National Academy of Sciences, 108, 2651-2655 (2011).

https://doi.org/10.1073/pnas.1015862108

[16] Fullenkamp D. E., He L., Barrett D. G., Burghardt W. R., Messersmith P. B.: Mussel-inspired histidine-based transient network metal coordination hydrogels. Macromolecules, 46, 1167-1174 (2013).

https://doi.org/10.1021/ma301791n

[17] Enke M., Bode S., Vitz J., Schacher F. H., Harrington M. J., Hager M. D., Schubert U. S.: Self-healing response in supramolecular polymers based on reversible zinchistidine interactions. Polymer, 69, 274-282 (2015). https://doi.org/10.1016/j.polymer.2015.03.068

[18] La Scala J., Wool R. P.: Property analysis of triglyceride-based thermosets. Polymer, 46, 61-69 (2005). https://doi.org/10.1016/j.polymer.2004.11.002

[19] Mozhdehi D., Neal J. A., Grindy S. C., Cordeau Y., Ayala S., Holten-Andersen N., Guan Z.: Tuning dynamic mechanical response in metallopolymer networks through simultaneous control of structural and temporal properties of the networks. Macromolecules, 49, 6310 6321 (2016). https://doi.org/10.1021/acs.macromol.6b01626

[20] Xia N. N., Xiong X. M., Wang J., Rong M. Z., Zhang M. Q.: A seawater triggered dynamic coordinate bond and its application for underwater self-healing and reclaiming of lipophilic polymer. Chemical Science, 7, 2736-2742 (2016). https://doi.org/10.1039/C5SC03483C 
[21] Tang J., Li J., Vlassak J. J., Suo Z.: Fatigue fracture of hydrogels. Extreme Mechanics Letters, 10, 24-31 (2017).

https://doi.org/10.1016/j.eml.2016.09.010

[22] Barrett D. G., Fullenkamp D. E., He L., Holten-Andersen N., Lee K. Y. C., Messersmith P. B.: pH-based regulation of hydrogel mechanical properties through musselinspired chemistry and processing. Advanced Functional Materials, 23, 1111-1119 (2013). https://doi.org/10.1002/adfm.201201922

[23] Xia N. N., Rong M. Z., Zhang M. Q., Kuo S-W.: Stress intensification - An abnormal phenomenon observed during stress relaxation of dynamic coordination polymer. Express Polymer Letters, 10, 742-749 (2016). https://doi.org/10.3144/expresspolymlett.2016.68
[24] Lei Y., Shan S., Lin Y., Zhang A.: Network reconfiguration and unusual stress intensification of a dynamic reversible polyimine elastomer. Polymer, 186, 122031/1122031/8 (2020). https://doi.org/10.1016/j.polymer.2019.122031

[25] Li Y., Zhang Z. P., Mo W. J., Rong M. Z., Zhang M. Q., Liu D.: Photo-induced topological self-reorganization and self-growth of polymer based on dynamic reversible aromatic pinacol units. Polymer, 192, 122299/1122299/10 (2020). https://doi.org/10.1016/j.polymer.2020.122299

[26] Zhang M. Q.: Repeated self-healing of wider cracks in polymers. Express Polymer Letters, 14, 895 (2020). https://doi.org/10.3144/expresspolymlett.2020.73 